\title{
Operation Analysis of Organic Rankine Cycle under Variable Conditions and Comparison confirmation of simulation calculation
}

\author{
Chen Xiaoqing ${ }^{1}$, Jiang Weiting ${ }^{1}$, Cao Xianchang ${ }^{2}$, Zhang Li'ang ${ }^{1}$, Chen Chi $^{2}$, Chen Zhiliang ${ }^{2}$, Yang Yiqing ${ }^{1}$ and Pan \\ Weiguo $^{1}$ \\ ${ }^{1}$ Shanghai University of Electric Power, Shanghai, China \\ ${ }^{2}$ Shanghai Baosteel Energy Technology Company, Shanghai, China
}

\begin{abstract}
The initial simulation calculation of the ORC power generation system was carried out using the software Aspen Plus, and the simulation data matched with the design conditions were obtained. According to the specific structure of the evaporator and superheater in the ORC power generation system and the characteristics of the software Aspen EDR, a new simulation calculation method is proposed: structural simulation calculation method. The calculation method and the direct simulation calculation method are used to carry out simulation comparison to find out the regularity of the change of waste heat resources, and it is convenient to further analyze and control the ORC power generation system.
\end{abstract}

\section{Introduction}

The researches of the Organic Rankine Cycle (ORC) technology began in $1924^{[1]}$. In the 1960 s, some test prototypes were developed. In the 1970 s, due to the outbreak of the oil crisis, a lot of researches on this technology were carried out. However, the market size of this technology was small (mainly used in waste heat recovery and new energy fields), and until the late 1990s, ORC power generation systems began to be widely used.

In an organic Rankine cycle power generation system, it is important to select the right organic working fluid because the difference in organic working fluid affects the entire system. In view of this aspect: Michele Tavano ${ }^{[2]}$ compared the mixed working fluid with the pure working fluid, and the results show that the optimized mechanical power can increase the recovered mechanical power by about 3 percentage points. Heberle $^{[3]}$ studied and compared the thermal properties of R227ea/R245fa and isobutylene/isopentane. The conclusion shows that the performance of $\mathrm{R} 227$ ea/R245fa mixed working fluid is better under the working condition of $80^{\circ} \mathrm{C}-180^{\circ} \mathrm{C}$. Lecompte ${ }^{[4]}$ analyzed that the power output of the binary mixture increased by $30 \%$ compared to the pure fluid, and in some cases the thermal efficiency increased by more than $15 \%$. Heberle et al. ${ }^{[5]}$ had also shown that anisotropic mixtures can improve the efficiency of organic Rankine cycle systems. Papadopoulos $^{[6]}$, Lampe ${ }^{[7]}$ developed and applied advanced computer-aided molecular design (CAMD) methods to identify or design optimal fluids for ORC systems. Andreasen,J.G ${ }^{[8]}$ studied the thermodynamic properties of mixture working fluids, developed and utilized genetic algorithms, and selected suitable organic mixed working fluids from the composition database. Markus $\mathrm{P}^{[9]}$ studied the thermal degradation characteristics of organic matter MM. At $300{ }^{\circ} \mathrm{C}$, the annual degradation rate of organic working medium MM is less than $3.5 \%$.

On the other hand, researches on ORC power generation technology focuses on the design and optimization of expanders. In 1987, Verneau ${ }^{[10]}$ used FC75 as the working fluid, designed a single/two-stage axial flow turbine. Kang ${ }^{[11]}$ proposed a high-speed radial turbine with R245fa as the working fluid. The measured output power can reach $32.7 \mathrm{kw}$ and the turbine efficiency can reach 78.7\%. T.Z. Kaczmarczyk ${ }^{[12]}$ established an organic Rankine cycle system test bench with a miniature radial turbine with HFE7100 as the working fluid. A.P. Weiß ${ }^{[13]}$ studied various turbines and considered that single-stage axial flow turbines can meet the requirements of small volume and high expansion ratio. P. R. Fernande $z^{[14]}$ proposed a complete method for shape optimization of ORC turbine blades. Kiyarash Rahbar ${ }^{[15]}$ proposed a method for achieving maximum efficiency optimization of a radial ORC turbine using mean-line modeling and genetic algorithm (GA). Enrico Rinaldi ${ }^{[16]}$ first studied the single-stage high expansion ratio ORC radial turbine under non-design conditions using quasi-three-dimensional numerical simulation method, and proposed a kind of unstable CFD simulation. 
While conducting experimental researches on the organic Rankine cycle, some scientists have studied their practical applications. Christopher $\mathrm{R}^{[17]}$ have been working on the application of organic Rankine cycle power generation systems on heavy duty road trucks. D. Serrano ${ }^{[18]}$ used the organic Rankine cycle to recover the exhaust heat of the train. Yari ${ }^{[19]}$ studied the efficiency of different ways of organic Rankine cycle for gas turbine waste heat recoveryt. $\mathrm{Gao}^{[20]}$ proposed a method for recovering exhaust heat from a turbocharged diesel engine using an organic Rankine cycle power generation system. Kévin $\mathrm{R}^{[21]}$ studied the application of small turbines in the waste heat recovery of automotive internal combustion engines. John $\mathrm{H}^{[22]}$ studied the application of the organic Rankine cycle in natural gas plants. Jan Wajs ${ }^{[23]}$ proposed a new small shell-and-tube type annular microchannel heat exchanger as a condenser for domestic micro-thermal power plant research.

Due to the fact that there is less actual simulation of the running organic Rankine cycle power generation system in the mainstream research direction, the accuracy of the organic Rankine cycle simulation system under variable operating conditions is rarely considered. This topic used Aspen Plus to selected a factory's ORC power generation system as the object to model, simulated its data changes under variable working conditions, and compared the actual data to draw conclusions. The ORC system is a Rankine cycle with organic matter as the working fluid. It consists of four basic components: evaporator, turboexpander, condenser, and working fluid pump ${ }^{[24]}$.

\section{Preliminary simulation}

\subsection{Overview of ORC Units in Operation}

The object of the simulation was the low-temperature waste heat ORC power generation system of the three-sinter ring cooler of a factory in Shanghai. The low-temperature section waste heat recovery process consists of a closed circulating hot water system, an ORC generator set and a cooling water circulation system. According to the actual ORC unit structure, a preliminary model structure was established in Aspen Plus as shown in Fig. 1.

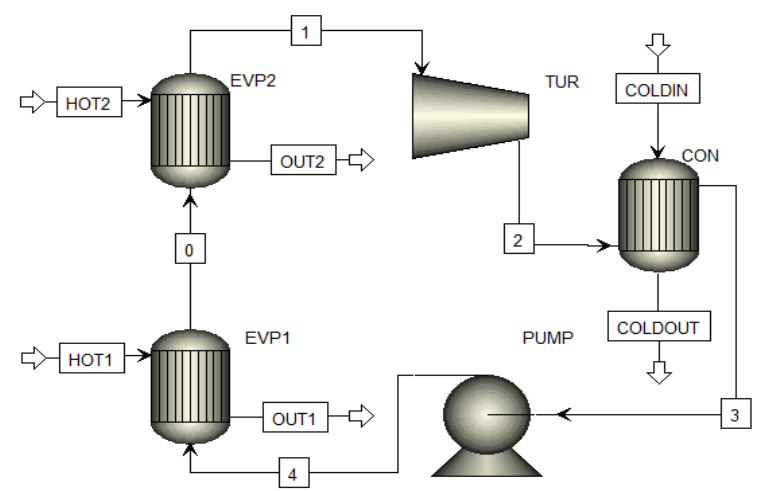

Fig.1. Preliminary model structure
EVP1 represents the evaporator, and the heat source used $220 \mathrm{t} / \mathrm{h}$ and $150^{\circ} \mathrm{C}$ hot water; EVP2 represents overheating, The steam is used as a heat source of $10 \mathrm{t} / \mathrm{h}$ and $180^{\circ} \mathrm{C}$; the TUR represents a expander with an isentropic efficiency of $80 \%$ and a mechanical efficiency of $85 \%$; CON stands for a condenser, and the cold source is about $23^{\circ} \mathrm{C}, 1620 \mathrm{t} / \mathrm{h}$ normal temperature water; PUMP is a working fluid pump with an isentropic efficiency of $85 \%$ and a mechanical efficiency of $85 \%$.

\subsection{Simulated an already running unit with Aspen Plus}

First, the global characteristics were set. In the process simulation, two kinds of fluids were involved: organic working fluid R245fa and water. The physical method chosen in this paper was the RK-SOAVE equation of state, which was often used in systems using organic working fluids.

Then input the logistics parameters and module parameters in the system, The mass flow rate of organic working fluid R245fa was $88 \mathrm{~kg} / \mathrm{s}$, the evaporation pressure was set to $2.04 \mathrm{MPa}$, the condensing pressure was set to $0.2 \mathrm{MPa}$. Each of the external streams must input three of the specific parameters of temperature, pressure, dryness, and flow. Each model must entered different parameters that the module needs to enter.

After inputting the above data, the preliminary running simulation results can be obtained, and the simulation results of each module in each cycle were uniformly represented by using a table, as shown in Table 1.

Table 1. Simulation results of various components of the system

\begin{tabular}{ccccc}
\hline equipment & $\begin{array}{c}\text { Inlet } \\
\text { temperatur } \\
\mathrm{e} \\
\left({ }^{\circ} \mathrm{C}\right)\end{array}$ & $\begin{array}{c}\text { outlet } \\
\text { temperature } \\
\left({ }^{\circ} \mathrm{C}\right)\end{array}$ & $\begin{array}{c}\text { Fluid } \\
\text { flow rate } \\
(\mathrm{Kg} / \mathrm{s})\end{array}$ & $\begin{array}{c}\text { Energy } \\
(\mathrm{MW})\end{array}$ \\
\hline evaporator & 33.89 & 122.4 & 88 & 16.42 \\
Superheater & 122.4 & 126.13 & 88 & 5.77 \\
Turbine & 126.13 & 64.69 & 88 & 2.66 \\
condenser & 64.69 & 33 & 88 & 19.21 \\
pump & 33 & 33.89 & 88 & 0.17 \\
\hline
\end{tabular}

Under the set condition parameters, the simulated thermal efficiency value was calculated according to Equation 1 as:

$$
\begin{aligned}
& \eta_{\mathrm{c}}=\frac{\mathrm{w}_{\text {net }}}{Q_{C}}=\frac{2.66-0.17}{16.42+5.77}=11.22 \% \\
& \eta_{\mathrm{c}}-\text { Cyclic thermal efficiency, } \% ; \\
& W_{\text {net }}-\text { System power, MW; } \\
& Q_{\mathrm{c}}-\text { System heat absorption, MW. }
\end{aligned}
$$

According to Equation 1, it can be concluded that the system cycle efficiency was $11.22 \%$ under normal 
operating conditions. However, due to the instability of the waste heat resources in the industrial park, the ORC power generation system cannot met the design conditions during normal operation, and was often operated at low load. In order to simulated the parameter changes during the operation of the ORC power generation system, the ORC simulation system needs to be further designed and calculated.

\section{Comparison confirmation of simulation calculation}

\section{1 simulation calculation}

\subsubsection{Structural Simulation calculation}

Since the Aspen Plus EDR does not have a structure similar to the actual running ORC system, the simulation results may be biased due to structural errors during the simulation of the superheater. if wanted to simulate the superheater in accordance with the actual situation, it need to obtained the specific parameters of the working point of the two exit points of the evaporator.

Although the software only gaves a working fluid export parameter when simulating, that was, the working fluid parameters of the two export working fluids were mixed, the temperature of both outlets was not marked. However, the temperature of the two outlets of the housing can be seen on the analog interface, as shown in Figure 2. It can be seen from the figure that the temperature of the left working outlet point 1 was significantly higher than the right exit point 2 and also higher than the saturation temperature. Therefore, the working outlet of the left exited point 1 is saturated or superheated steam. The working fluid flow rate of the two outlets was regarded as half of the total flow rate, and the specific parameters of the two export working fluids, that was, the working temperature and dryness, can be obtained according to the mixed parameters. Stream Temperatures

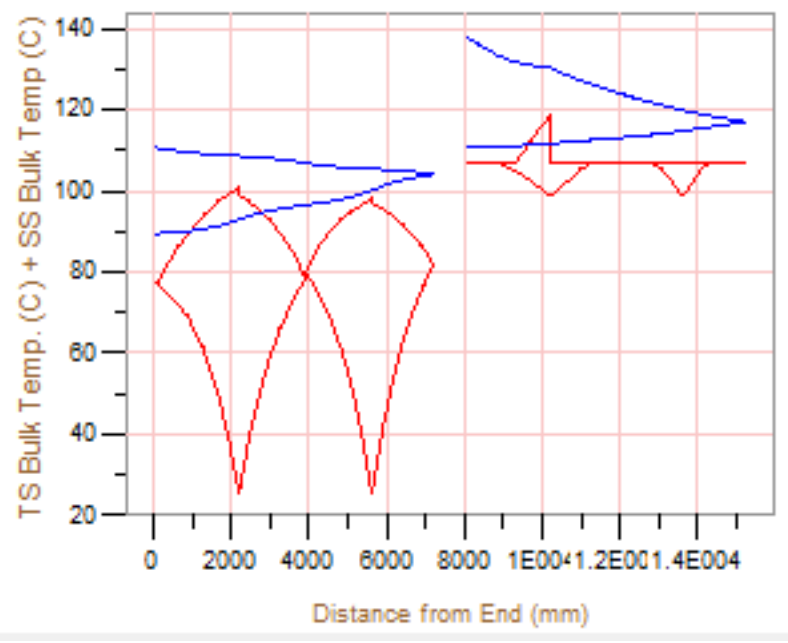

Fig.2. Schematic diagram of fluid temperature in the evaporator housing

The total heat transfer of hot water can be obtained by formula 2 . According to formula 3 , the total heat transfer of working fluid at outlet point 2 can be obtained by subtracting the heat transfer of working fluid at outlet point 1 from the total heat transfer. Finally, the enthalpy of the working fluid at outlet point 2 was obtained according to the working fluid 4 . The enthalpy $\mathrm{h}$ of each point was obtained by software REFPROP.

$$
\begin{aligned}
& Q_{\text {total }}=\left(\mathrm{h}_{\text {Win }}-\mathrm{h}_{\text {Wout }}\right) \mathrm{m}_{W} \\
& Q_{2}=Q_{\text {total }}-Q_{1}=Q_{\text {total }}-\frac{\left(\mathrm{h}_{\text {out } 1}-\mathrm{h}_{\text {in }}\right) \mathrm{m}}{2} \\
& Q_{2}=\frac{\left(\mathrm{X}-\mathrm{h}_{\text {in }}\right) \mathrm{m}}{2}
\end{aligned}
$$

$\mathrm{Q}_{\text {total }}$ - total heat transfer of evaporator;

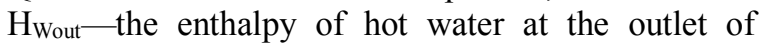
evaporator;

$\mathrm{H}_{\text {Win }}$-Enthalpy value of imported hot water of evaporator;

$\mathrm{M}_{\mathrm{W}}$ - evaporator hot water flow, $\mathrm{kg} / \mathrm{s}$;

$\mathrm{Q}_{1}$ - heat transfer of working fluid at outlet 1;

$\mathrm{Q}_{2}$ - heat transfer of working fluid at outlet 2;

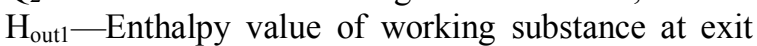
point 1 ;

$\mathrm{X}$-Enthalpy value of working substance for export point 2 .

After the enthalpy value of the working substance at outlet 2 was obtained, it can be judged whether the working substance was in two-phase state or not. If it was in two-phase state, the dryness of the working substance can be calculated by formula 5 .

$$
\mathrm{h}_{\text {gas }} Y+\mathrm{h}_{\text {liquid }}(1-\mathrm{Y})=\mathrm{X}
$$

Y-Dryness of working fluid at outlet point 2;

Hgas - the enthalpy of working substance at outlet point 2 when it is gaseous;

Hliquid-Enthalpy value at outlet point 2 when working fluid is liquid.

\subsubsection{Direct simulation}

The direct simulation calculation method is to select the heat exchanger structure consistent with the evaporator and superheater in the ORC power generation system, and directly input the parameters of the working fluid parameters of the evaporator outlet to the exit point of the superheater (This parameter was the working parameter of the two evaporator outlet point parameters.). Since the calculation method was relatively straightforward and did not take into account the connection mode of the evaporator and the superheater in actual operation, the method was called the direct simulation calculation method.

\subsubsection{Comparison of direct simulation calculation and structural simulation calculation}

The mixed superheater outlet working medium has reached a gaseous state. The temperature of the superheater outlet working fluid obtained by the two methods was compared, as shown in Table 2. It can be seen that when using the direct simulation calculation 
method, the deviation value was small, and the fluctuation value was within $+10 \%$. When the structural simulation calculation method was used for the simulation calculation, the deviation value fluctuates greatly and fluctuates within $\pm 20 \%$. Therefore, through the data comparison, it can be concluded that the direct simulation method can be used to obtain a more realistic value, and the value has a certain regularity.

Table 2. Comparison of two simulation algorithm parameters

\begin{tabular}{ccccc}
\hline $\begin{array}{c}\text { Actual } \\
\text { operation } \\
\left({ }^{\circ} \mathrm{C}\right)\end{array}$ & $\begin{array}{c}\text { Direct } \\
\text { simulatio } \\
\mathrm{n}\end{array}$ & $\begin{array}{c}\text { Deviation } \\
(\%)\end{array}$ & $\begin{array}{c}\text { Structural } \\
\text { simulatio } \\
\left({ }^{\circ} \mathrm{C}\right)\end{array}$ & $\begin{array}{c}\text { Deviation } \\
(\%)\end{array}$ \\
\hline 128.8 & 133 & 3.26 & 122.5 & \\
114.6 & 121 & 5.58 & 130 & -4.89 \\
122 & 125 & 2.46 & 134 & 9.84 \\
115 & 124 & 7.83 & 138 & 20 \\
\hline
\end{tabular}

\subsection{Analysis of simulation results of direct simulation calculation}

Simulate calculations using direct simulation, the working fluid pump outlet data was input into the Aspen EDR, and the evaporator superheater module was simulated. The working fluid parameters of the superheater outlet were obtained and compared with the actual working fluid export parameters, as shown in Fig. 4. Then input the simulated superheater outlet working parameters into the turbine module in Aspen Plus, simulated the system power, and compared the results with the actual power.

The 20 sets of data selected in this simulation have a large span, the superheater outlet temperature was from $96{ }^{\circ} \mathrm{C}$ to $126{ }^{\circ} \mathrm{C}$, and the attack power was from $1 \mathrm{MW}$ to $1.9 \mathrm{MW}$. From the comparison of the simulated outlet temperature and the actual outlet temperature, the simulation of the turbine power and the actual work power: the error was within $\pm 10 \%$, and presented a certain regularity. It can be concluded that the direct simulation calculation method in Aspen Plus can be used to simulate the ORC power generation system, and the simulation parameters which were in good agreement with the actual parameters can be obtained.

\subsection{Simulate using direct simulation}

As can be seen from Figure 3, the simulated heat exchanger outlet temperature and turbine work were higher than the actual data. Compared with the simulated turbine power, the simulation data of the heat exchanger outlet temperature fluctuates greatly. However, the power of the turbine was not only considering the outlet temperature, but also the pressure of the exporting work. Therefore, when simulated the power of the turbine, the error would decrease and it would show a certain linearity compared with the actual power. In future applications, the correction factor can be set according to the error between the simulated calculation parameters and the actual parameters, which can improved the stability of the simulation data.
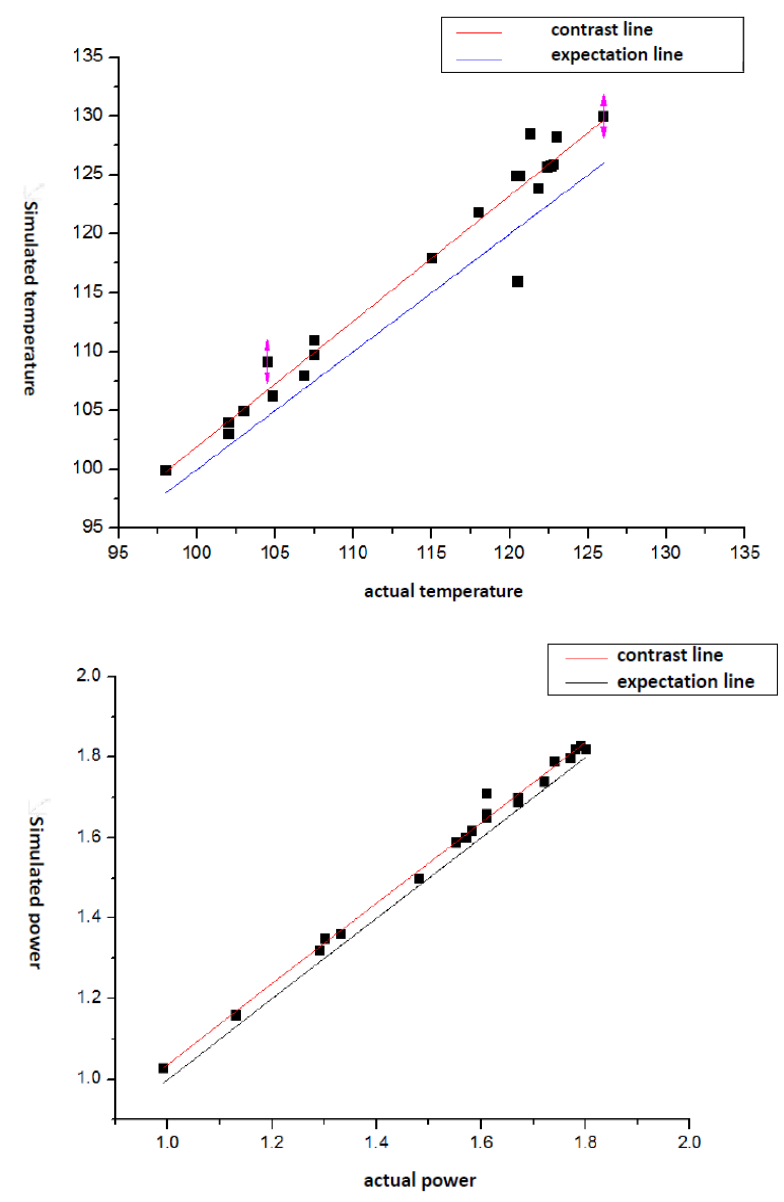

Fig.3. Comparison of actual parameters and simulation parameters

\section{Conclusion}

(1) Using software Aspen Plus to carry out preliminary simulation study on low temperature waste heat ORC power generation system, using RK-SOAVE as physical method, the heat exchanger assembly adopts preliminary design, and does not design parameters such as heat exchanger size, number of tubes, length of pipe, etc. After inputting the basic parameters, it is found that the design conditions of the ORC power generation system are basically the same, that is, the software Aspen Plus has relatively high accuracy when designing the working condition of the ORC power generation system. It can be seen from the simulation results that under full load operation, the cycle efficiency of the ORC power generation system can reach $11.22 \%$, and the design power of the turbine is $2.66 \mathrm{MW}$.

(2) When the ORC power generation system was operated under variable operating conditions, the structure of the ORC power generation system needs to be further simulated. The software Aspen Plus was used to simulate the evaporator and superheater modules in the ORC power generation system. After the heat exchanger module was simulated, 20 sets of data with stable operation are selected, and the ORC power generation system was simulated by using the structural simulation calculation method and the direct simulation 
calculation method. Compared the two calculation methods, it can be seen that the simulation data obtained by the direct simulation calculation was closer to the actual operation value. When the direct simulation calculation method was used to simulate the ORC power generation system under variable working conditions, the simulated data was compared with the real data deviation value within $10 \%$, and a certain regularity was presented.

\section{Reference}

1. Z.M. Mercang, Hemrlej, L. Kaufmamn, Energy, 45,407-415(2012)

2. R. Scaccabarozzi, M. Tavano, C.M. Invernizzi, Energy Procedia, 129, 168-175(2017)

3. F. Heberle, M. Preißinger, D. Brüggemann, Renew Energy, 37,364-370(2012)

4. S. Lecompte, B. Ameel, D. Ziviani, Energy Convers. Manage. 85:727-739(2014)

5. F. Heberle, D. Brüggemann, Renew Energy, 37,364-370(2012)

6. A.I. Papadopoulos, M. Stijepovic, P. Linke, Appl. Therm. Eng. 2010, 30,760-769(2010)

7. M. Lampe, C. Kirmse, E. Sauer, Comput.-Aided Chem. Eng. 34,357-362(2014)

8. J.G. Andreasen, U. Larsen, T. Knudsen, Energy, 73,204-213(2014)

9. M. Preißinger, D. Brüggemann, ASME ORC 2015, (Brussels, Belgium. 2015)

10. A. Verneau, Von Karman Institute for Fluid Dynamics,(Lecture Series , Brussels, 1987)

11. S.H. Kang, D.H. Chung, Radial Turbine, 1037-1043(2011)

12. Z. Tomasz, Kaczmarczyk, G. Żywica, E. Ihnatowicz, The International Seminar on Organic Rankine Cycle Power Systems(2015)

13. A.P. Weiß, ASME ORC 2015, (Brussels, Belgium. 2015)

14. P. Rodriguez-Fernandez, G. Persico, ASME ORC 2015, (Brussels, Belgium. 2015)

15. K. Rahbar, S. Mahmoud, K. Raya, Al-Dadah, $A S M E$ ORC 2015, (Brussels, Belgium. 2015)

16. E. Rinaldi, R. Pecnik, P. Colonna, ASME ORC 2015, (Brussels, Belgium. 2015)

17. C.R. Nelson, ASME ORC 2015, (Brussels, Belgium. 2015)

18. D. Serrano, P. Smague, P. Tona1, P. Leduc, A.C. Mintsa, A. Leroux, P. Chevalier, ASME ORC 2015 , (Brussels, Belgium. 2015)

19. M. Yari, A.S. Mehr, V. Zare, S.M.S. Mahmoudi, M.A. Rosen, Energy, 712-722(2015)

20. W.Z. Gao, J.M. Zhai, G.H. Li, Energy, 55,226-235(2013)

21. K. ROSSET, V. Mounier, E. Guenat, O. Pajot, J. Schiffmann, ASME ORC 2015, (Brussels, Belgium.
2015)

22. J. Harinck, L. Calderazzi, P. Colonna, H. Polderman, ASME ORC 2015, (Brussels, Belgium. 2015)

23. J. Wajs, Energy, 157,853-861(2018)

24. F. Xun, Energy Convers. Technol. 387-391(2010) 